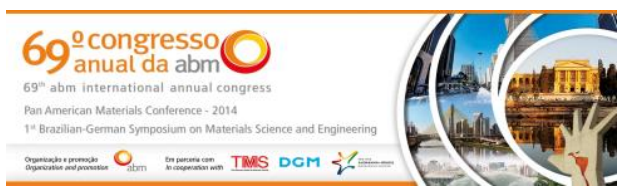

Tema: Gestão da Inovação

\title{
PROSPECÇÃO TECNOLÓGICA EM MATERIAIS À BASE DE MAGNÉSIO PARA ARMAZENAMENTO DE HIDROGÊNIO A PARTIR DE DOCUMENTOS DE PATENTES*
}

\author{
Lucas Faccioni Chanchetti ${ }^{1}$ \\ Douglas Henrique Milanez ${ }^{2}$ \\ Daniel Rodrigo Leiva ${ }^{3}$ \\ Leandro Innocentini Lopes de Faria ${ }^{3}$ \\ Tomaz Toshimi Ishikawa ${ }^{4}$
}

\section{Resumo}

A utilização do hidrogênio em Células a Combustível para a geração de energia embarcada é uma alternativa promissora para o futuro da indústria automobilística, uma vez que o sistema é eficiente, possui alta densidade energética e é ambientalmente limpo. No entanto sistemas avançados para o armazenamento do hidrogênio são necessários, já que este possui uma densidade baixíssima. Entre as principais opções pesquisadas estão os hidretos à base de magnésio. Neste trabalho foi feita uma análise das patentes depositadas no mundo sobre estes materiais, mapeando os principais atores, evolução estocástica e as tendências tecnológicas do setor. Foi encontrada uma queda expressiva no patenteamento após 2008, o que pode sugerir um início de estágio de amadurecimento tecnológico, além de menos de $10 \%$ das famílias de patentes terem sido depositadas no Brasil, o que parece indicar que este não é visto como um mercado promissor para a tecnologia

Palavras-chave: Prospecção tecnológica; Energias renováveis; Hidretos metálicos; Patentes.

\section{TECHNOLOGICAL FORECAST IN MAGNESIUM BASED MATERIALS FOR HYDROGEN STORAGE USING PATENT DOCUMENTS}

\section{Abstract}

The use of hydrogen in Fuel Cells for onboard energy generation is a promising alternative for the automotive industry, as the system is efficient, has a high energy density and is environmentally benign. However, advanced hydrogen storage systems are required, as the gas has a very low density. Among the options are magnesium-based hydrides. In this work, worldwide deposited patent documents on these materials were analyzed, mapping the main actors, evolution and technological tendencies for the sector. A considerable drop in patenting was found after 2008, which could suggest technological maturing could have started. Also, less than $10 \%$ of the patent families were deposited in Brazil, indicating it is not seen as a promising market for this technology.

Keywords: Technological forecasting; Renewable energies; Metal hydrides; Patents.

1 Engenheiro de Materiais, Mestrando, Núcleo de Informação Tecnológica, Departamento de Engenharia de Materiais, Universidade Federal de São Carlos, São Carlos, SP, Brasil.

2 Engenheiro de Materiais, Mestre, Doutorando, Núcleo de Informação Tecnológica, Departamento de Engenharia de Materiais, Universidade Federal de São Carlos, São Carlos, SP, Brasil.

3 Engenheiro de Materiais, Professor Doutor, Núcleo de Informação Tecnológica, Departamento de Engenharia de Materiais, Universidade Federal de São Carlos, São Carlos, SP, Brasil.

4 Engenheiro de Materiais, Professor Doutor, Departamento de Engenharia de Materiais, Universidade Federal de São Carlos, São Carlos, SP, Brasil.

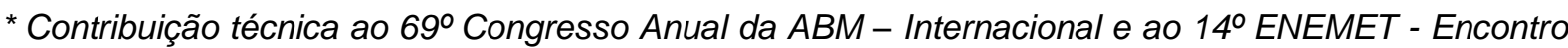
Nacional de Estudantes de Engenharia Metalúrgica, de Materiais e de Minas, 21 a 25 de julho de 2014, São Paulo, SP, Brasil.
} 


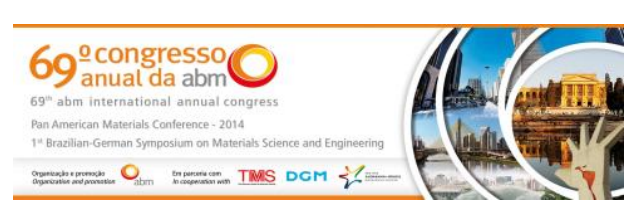

É importante diferenciar os conceitos de Patente, Documento de Patente e Família de Patentes. Patente é um direito exclusivo de exploração comercial de um invento, concedido pelo governo, em troca da publicação de seu Documento de Patente. Documento de Patente é o documento entregue no momento do depósito do pedido de patente, contendo a descrição do invento. Uma família de patentes consiste numa coleção de documentos de patentes, depositadas em diferentes escritórios, sobre uma mesma invenção (Uma vez que a abrangência do direito da patente é nacional) [8].

Neste trabalho, foi feita a análise bibliométrica de 538 documentos de patentes sobre materiais à base de magnésio para armazenamento de hidrogênio. Foram extraídos seus anos de depósito, países de origem e de depósito e titulares. As tecnologias abordadas foram levantadas através de mineração de texto usando a técnica Natural Language Processing (NLP) [7]. Os resultados foram compilados na forma de gráficos.

\section{MATERIAIS E MÉTODOS}

A coleta dos documentos de patentes foi realizada na base Derwent Innovations Index (DII). Esta base de dados possui as vantagens de ser multinacional e de consolidar as famílias de patentes em um único registro, além da grande versatilidade na utilização de caracteres coringa e operadores booleanos. O período de depósito considerado foi de 1990 em diante. A tabela 1 traz a expressão de busca utilizada para recuperação dos registros

Tabela 1. Expressão de busca utilizada

\begin{tabular}{|c|c|}
\hline \#1 & $\begin{array}{l}\text { ts=(hydrogen-storage OR storage-of-hydrogen) AND ts=(magnesium-hydride OR } \\
\text { mgh?\$\$ OR mg?h* OR mg??h* OR mg???h*) NOT ts=(mgkoh* OR mgk0h*) }\end{array}$ \\
\hline \#2 & $\begin{array}{l}\text { ip=f17c-011* AND ts=(magnesium OR "mg " OR mgh? } \$ \$ \text { OR mg?h* or mg??h* } \\
\text { OR mg???h*) and ts=(hydrogen or "h2 " or "h(2) ") NOT ts=(mgkoh* OR mgk0h*) }\end{array}$ \\
\hline \#3 & $\mathrm{ip}=\left(\mathrm{c} 01 \mathrm{~b}-003^{*}\right.$ AND c22c-023*) \\
\hline$\# 4$ & $\mathrm{ip}=\left(\mathrm{c} 01 \mathrm{~b}-006^{*}\right)$ and ts=(magnesium OR "mg ") \\
\hline$\# 5$ & \#4 AND ts=stor ${ }^{*}$ \\
\hline \#6 & \#4 AND ti=hydride $\$$ \\
\hline$\# 7$ & ts $=($ nickel-metal OR nimh OR nickel-hydrogen OR (battery NOT fuel) ) \\
\hline \#8 & ( \#1 OR \#2 OR \#3 OR \#5 OR \#6 ) NOT \#7 \\
\hline
\end{tabular}

Utilizando-se o software VantagePoint (versão 5.5) foram feitos a mineração, através do processo NLP, de palavras-chave dos campos título, resumo, descrição detalhada, foco tecnológico e vantagem, o agrupamento das palavras-chave mineradas por meio de thesauri, a contagem bibliométrica, a criação de listas e matrizes utilizando os campos originais dos registros e os obtidos pela mineração e o agrupamento de termos. A representação gráfica foi feita utilizando o Microsoft Excel.

\section{RESULTADOS E DISCUSSÃO}

A Figura 1 mostra o total de depósitos de patentes sobre o tema no mundo, de 1990 a 2011. Foram depositadas no total 538 patentes ou famílias de patentes. Para as famílias de patentes foi considerada apenas a data do primeiro depósito.

\footnotetext{
* Contribuição técnica ao $69^{\circ}$ Congresso Anual da ABM - Internacional e ao 14ํㅡㄹ ENEMET - Encontro Nacional de Estudantes de Engenharia Metalúrgica, de Materiais e de Minas, 21 a 25 de julho de 2014, São Paulo, SP, Brasil.
} 
A Figura 3 mostra a evolução temporal do patenteamento pelas principais empresas.

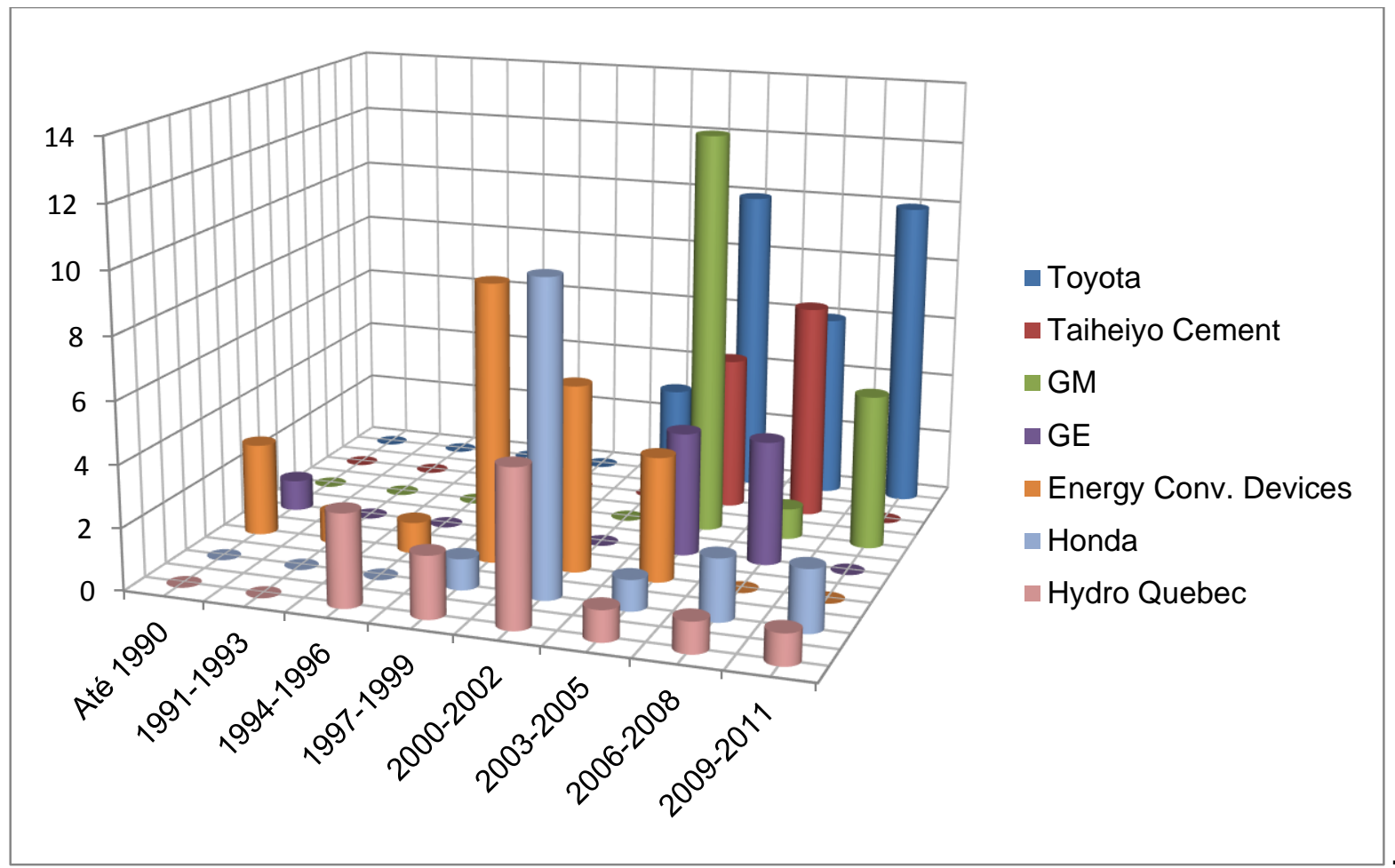

Figura 3. Tendências de patenteamento para as principais empresas.

A maior atenção foi dada à tecnologia pela maioria das empresas no período de 2000 a 2005. Nos últimos anos, apenas Toyota e GM dão sinais de retomada do interesse na tecnologia.

A figura 4 mostra a evolução temporal do patenteamento pelos principais institutos de pesquisa. 


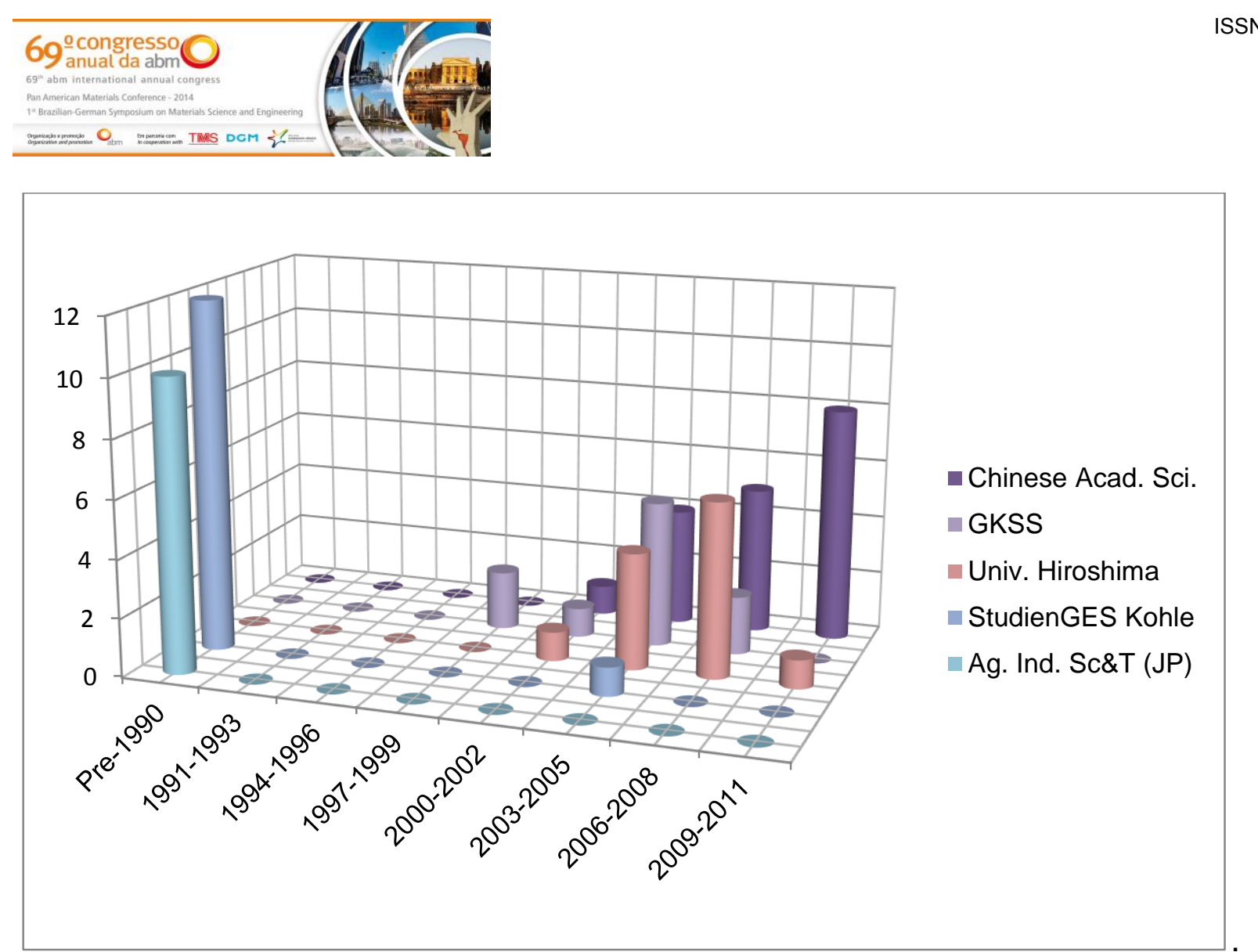

Figura 4. Tendências de patenteamento para os principais institutos de pesquisa.

Verificou-se uma separação entre dois grandes grupos: Os que patentearam sobre o tema nas décadas de 1970 e 1980, quando ocorreram os dois choques do petróleo, não retomaram seus esforços nos anos seguintes. Já ente os institutos que patentearam sobre o tema na década de 2000, o interesse no tema caiu drasticamente após 2008, com exceção da Academia Chinesa de Ciências, entidade que congrega diversos institutos de pesquisa daquele país, cujo interesse no tema é crescente.

As figuras 5 e 6 mostram respectivamente os escritórios de patentes de origem e os escritórios onde foram depositadas as famílias de patentes, percentualmente.

* Contribuição técnica ao $69^{\circ}$ Congresso Anual da ABM - Internacional e ao 14ํㅡㄹ ENEMET - Encontro Nacional de Estudantes de Engenharia Metalúrgica, de Materiais e de Minas, 21 a 25 de julho de 2014, São Paulo, SP, Brasil. 


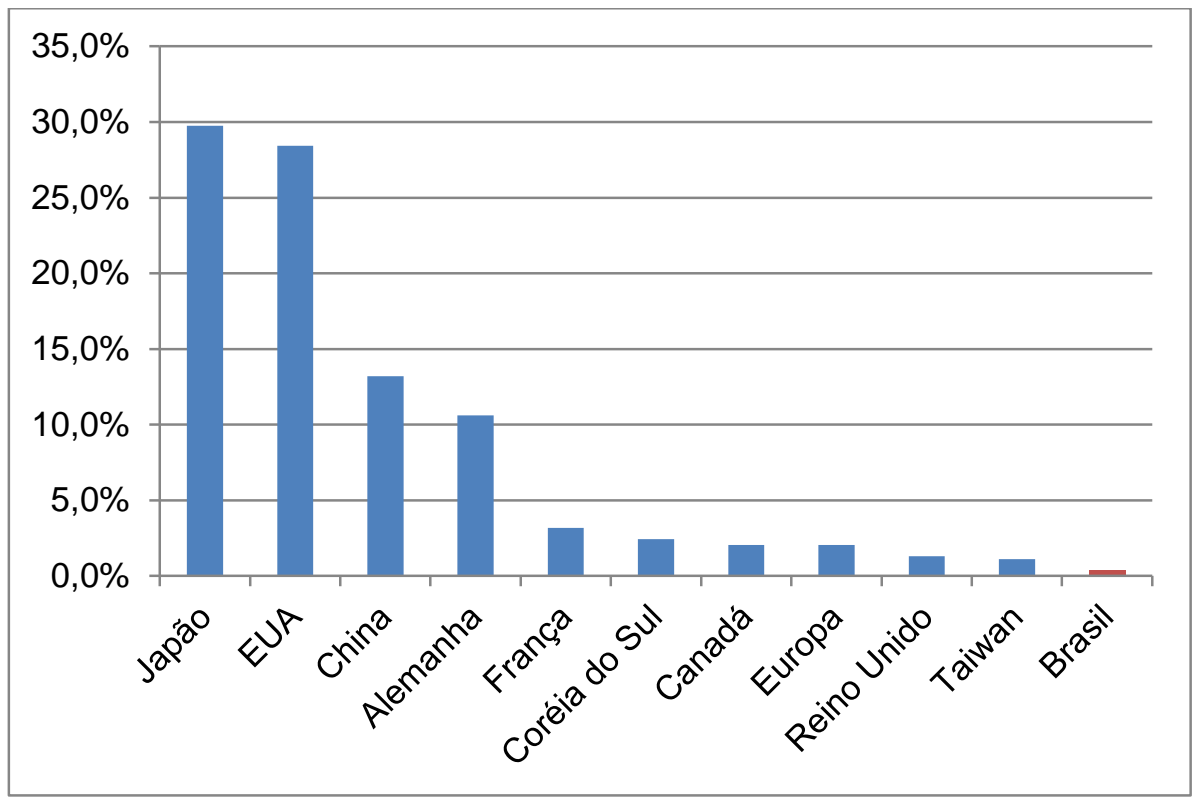

Figura 5. Escritórios de origem das patentes.

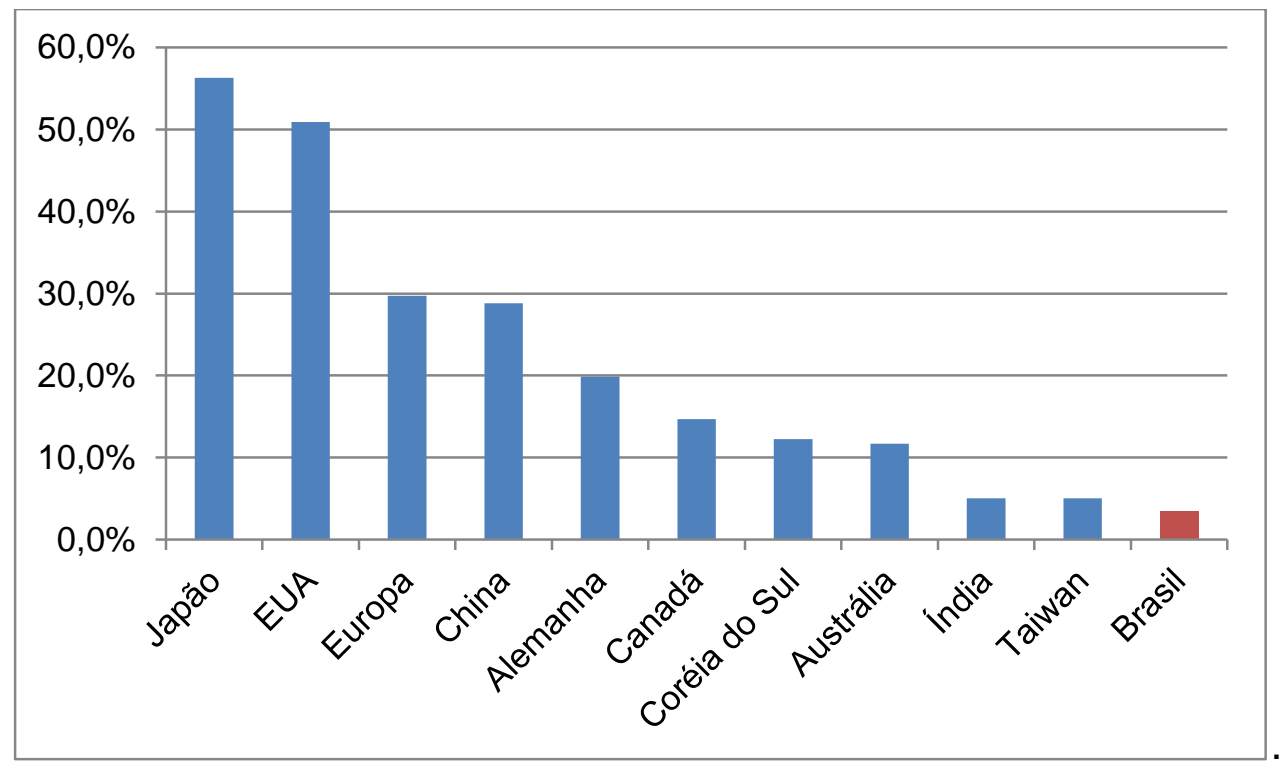

Figura 6. Escritórios em que as patentes foram depositadas.

EUA e Japão têm maior destaque frente aos outros mercados, depositando e possuindo praticamente 0 dobro de patentes dos mercados adjacentes. A alta correlação entre os gráficos é devida a um alto grau de proteção apenas no país de origem. Das 538 famílias de patentes, apenas 143 foram depositadas na TRIAD (Simultaneamente nos escritórios dos EUA, Japão e Europa). Destaca-se também a Austrália e o Canadá, com baixo patenteamento próprio, mas alto patenteamento estrangeiro, indicando serem mercados de grande interesse. O Brasil possui apenas duas patentes, depositadas apenas localmente por universidades, e menos de $5 \%$ das famílias de patentes foram protegidas no mercado brasileiro. Isto parece indicar que além de baixa competência no desenvolvimento destas tecnologias, o Brasil não é um mercado de potencial interesse para estas.

A figura 7 traz a distribuição dos tipos de hidretos tratados nos documentos de patentes.

* Contribuição técnica ao $69^{\circ}$ Congresso Anual da ABM - Internacional e ao 14ํㅡㄹ ENEMET - Encontro Nacional de Estudantes de Engenharia Metalúrgica, de Materiais e de Minas, 21 a 25 de julho de 2014, São Paulo, SP, Brasil. 


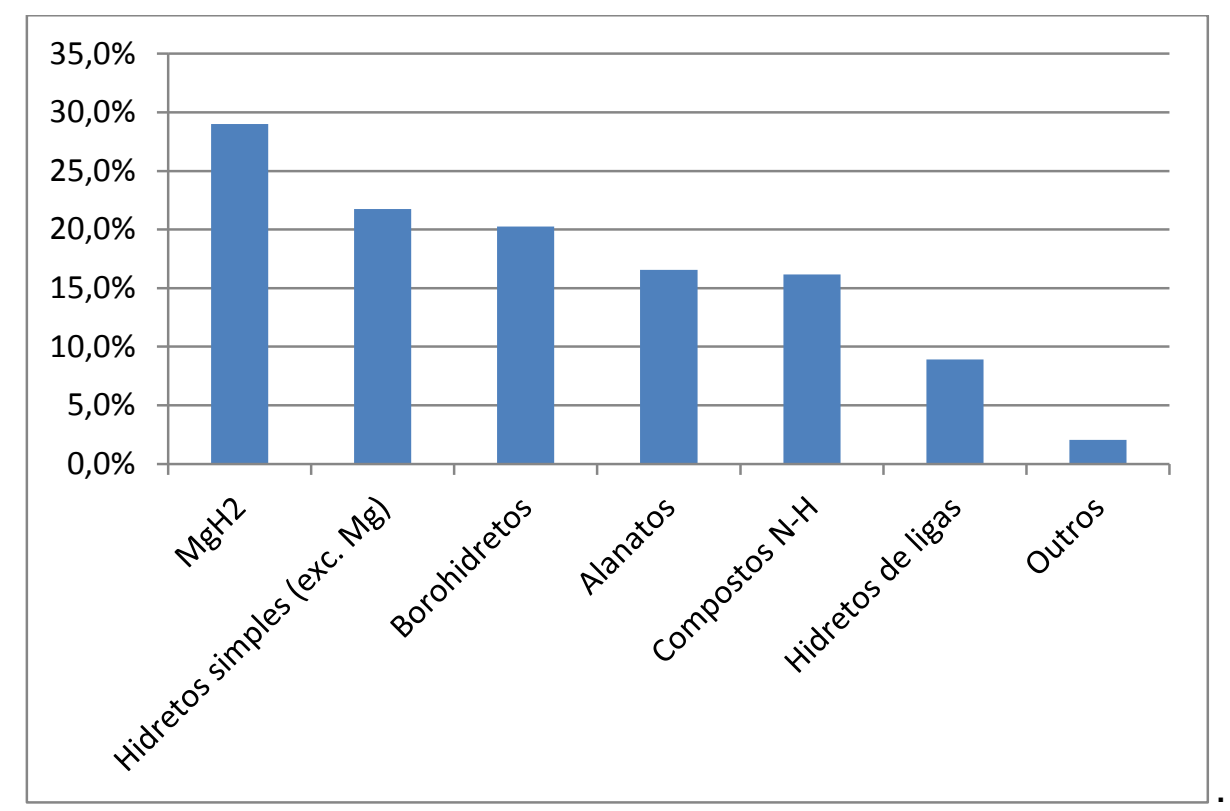

Figura 7. Tipos de hidretos abordados nas patentes.

Há uma predominância de hidretos metálicos simples, seguidos de hidretos químicos e complexos, e por último hidretos de ligas metálicas.

A figura 8 traz a distribuição dos outros elementos químicos, além do magnésio, citados nos documentos de patentes.

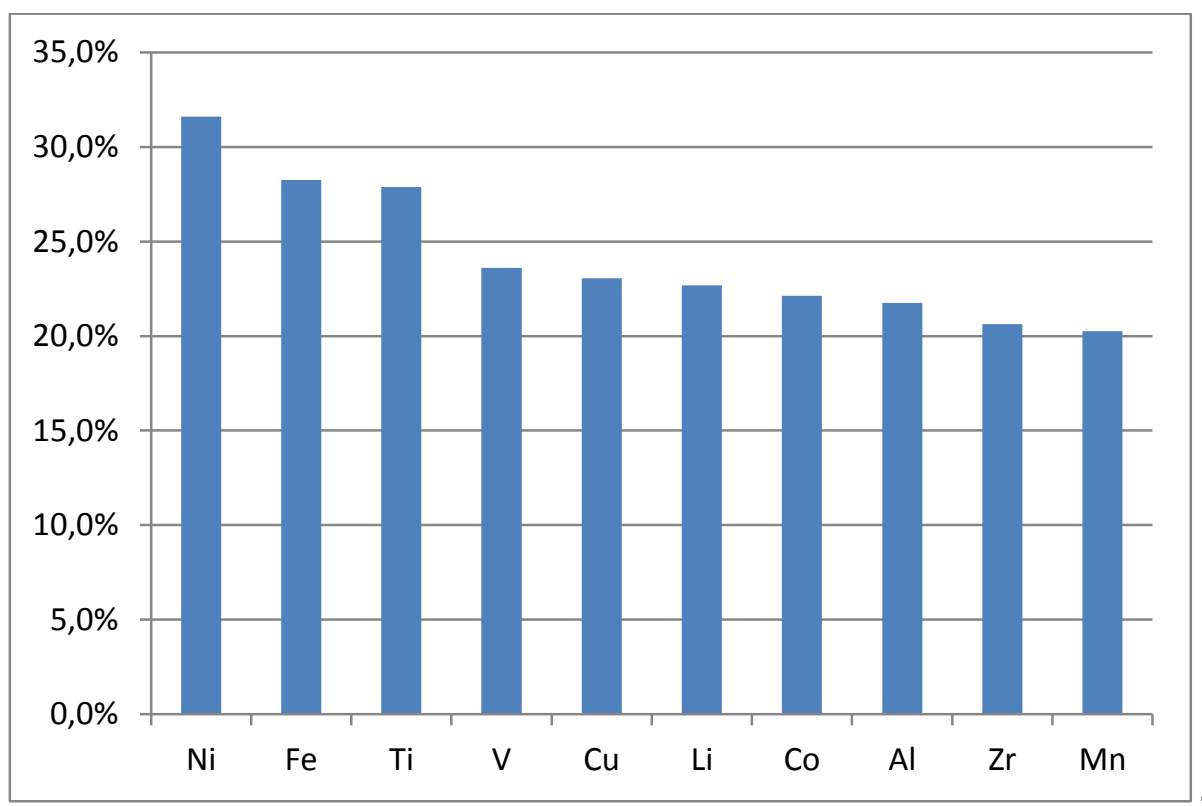

Figura 8. Elementos químicos mais citados nas patentes.

Os elementos de maior destaque são metais de transição, normalmente utilizados como aditivos e catalisadores para melhoria das propriedades chave dos hidretos puros, mas também como elementos de liga, além de lítio e alumínio, formadores de hidretos complexos de baixa densidade.

A figura 9 mostra a distribuição dos problemas tecnológicos tratados pelos documentos de patentes

\footnotetext{
* Contribuição técnica ao $69^{\circ}$ Congresso Anual da ABM - Internacional e ao 14ํㅡㄹ ENEMET - Encontro Nacional de Estudantes de Engenharia Metalúrgica, de Materiais e de Minas, 21 a 25 de julho de 2014, São Paulo, SP, Brasil.
} 

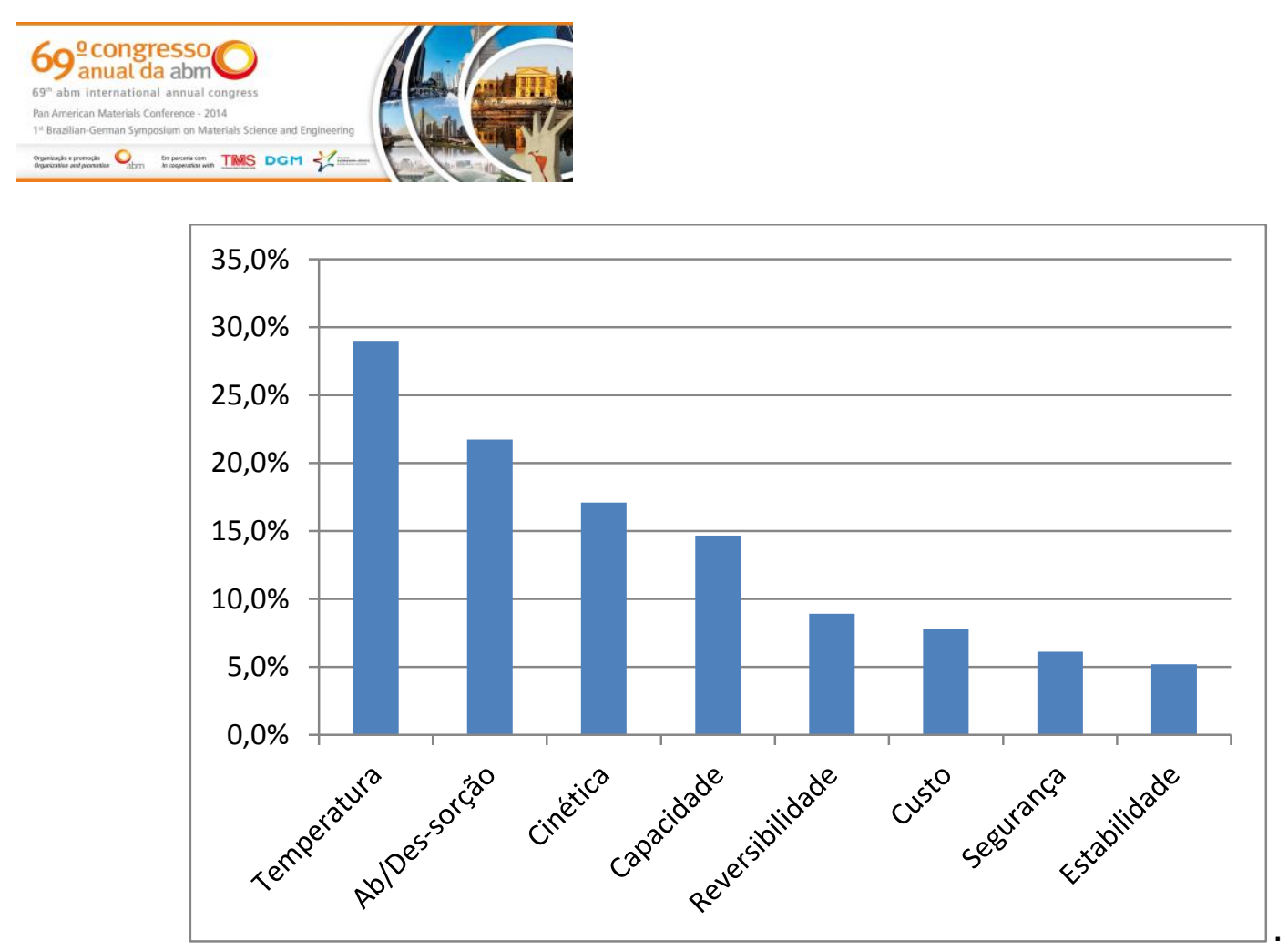

Figura 9. Problemas tecnológicos abordados.

Conforme esperado, os principais problemas a serem superados por estes materiais são a temperatura e a cinética de absorção e dessorção do hidrogênio. O custo aparece em 6임 lugar, com menos de $5 \%$ das patentes tratando do tema. Isto pode indicar que os desafios técnicos relacionados às propriedade físico-químicas destes materiais ainda são problemas maiores, que quando solucionados devem dar lugar a uma maior importância às questões econômicas.

A fim de exemplificar, seguem algumas decisões que poderiam ser tomadas com base nos indicadores propostos:

- Para uma empresa com intenção de construir infraestrutura em hidrogênio no Brasil, o baixo patenteamento parece indicar que, nos próximos 15 anos, não há interesse das empresas automobilísticas em comercializar tais tecnologias no mercado brasileiro. Caso a mesma tendência observada nos veículos híbridos seja seguida [10,11], podemos esperar uma defasagem de 15 a 20 anos entre o mercado brasileiro e o americano.

- Para um centro de pesquisas, especialmente com a intenção de licenciamento de tecnologia, direcionar os esforços para aspectos como reversibilidade e estabilidade dos materiais, temas menos explorados, mas de altíssima importância.

\section{CONCLUSÃO}

Foram analisados 538 documentos de patentes sobre materiais à base de magnésio para armazenamento de hidrogênio, considerando ano de depósito, países depositantes e de depósito, titulares e tecnologias abordadas. Houve um interesse crescente no tema a partir do fim da década de 1990, acompanhando o aumento da preocupação ambiental, porém este diminui após 2008, sendo que dos principais atores, apenas Toyota, GM e o Governo Chinês continuam apostando na tecnologia. De acordo com a literatura, o fato de as dificuldades técnicas terem se mostrado maiores que o esperado levou a um redirecionamento a outras tecnologias mais maduras, como baterias de lítio [12]. No entanto, estas alternativas não aliam as características de sustentabilidade e altas capacidades [13], de forma que a

\footnotetext{
* Contribuição técnica ao 69ำ Congresso Anual da ABM - Internacional e ao 14ํㅡㄹ ENEMET - Encontro Nacional de Estudantes de Engenharia Metalúrgica, de Materiais e de Minas, 21 a 25 de julho de 2014, São Paulo, SP, Brasil.
} 


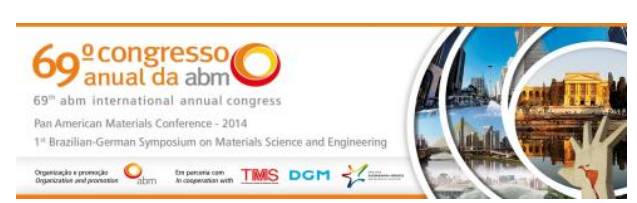

pesquisa e desenvolvimento dos materiais para armazenamento de hidrogênio devem continuar.

O Brasil não participa significativamente nem como depositante nem como destino do patenteamento, o que parece sugerir que este não é um mercado promissor para o atual estado da tecnologia.

\section{Agradecimentos}

Os autores agradecem à CAPES e à FAPESP (Processo 2012/16573-7) pelo financiamento, ao Núcleo de Informação Tecnológica em Materiais (NIT-Materiais) pela estrutura para o desenvolvimento do trabalho, e ao Programa de PósGraduação em Ciência e Engenharia de Materiais (PPGCEM) e ao Departamento de Engenharia de Materiais (DEMa) da Universidade Federal de São Carlos (UFSCar) pelo apoio institucional.

\section{REFERÊNCIAS}

1 Mekhilef S, Saidur R, Safari A. Comparative study of different fuel cell technologies. Renewable and Sustainable Energy Reviews. 2012;16(1):981-9.

2 Schlapbach L, Züttel A. Hydrogen-storage materials for mobile applications. Nature. 2001; 414(6861):353-8.

3 Varin RA, Czujko T, Wronski ZS. Nanomaterials for solid state hydrogen storage [Internet]. New York; London: Springer; 2009

4 Porter AL, Detampel MJ. Technology opportunities analysis. Technological Forecasting and Social Change. 1995; 49(3):237-55.

5 Faria LIL. Prospecção tecnológica em materiais: aumento da eficiência do tratamento bibliométrico. Aplicação na análise de tratamentos de superfície resistentes ao desgaste [Tese de Doutorado]. São Carlos: Universidade Federal de São Carlos; 2001.

6 Breitzman AF. Assessing an industry's R\&D focus rapidly: A case study using datadriven categorization in a consumer products area. Competitive Intelligence Review. 2000; 11(1):58-64.

7 Porter AL, Cunningham SW. Tech Mining: Exploiting New Technologies for Competitive Advantage. Hoboken: John Wiley \& Sons; 2004. 405 p.

8 Guia Básico - Patentes [página da internet]. Rio de Janeiro: INPI, 2014 [Acesso em 14 mar. 2014]. Disponível em: http://www.inpi.gov.br/portal/artigo/guia_basico_patentes

9 Nickel Metal-Hydride - BASF Catalysts - The Global Leader in Catalysis [página da internet]. Iselin: BASF [Acesso em 14 mar. 2014]. Disponível em: http://www.catalysts.basf.com/p02/USWeb-

Internet/catalysts/en/content/microsites/catalysts/prods-inds/batt-mats/NiMH

10 Toyota Prius turns 16: How the hot hybrid has changed over the years [página da internet]. Nova lorque: NY Daily News [Acesso em 12 Mai 2014]. Disponível em: http://www.nydailynews.com/autos/toyota-prius-turns-16-hot-hybrid-changed-yearsarticle-1.1385087

11 Toyota começa as vendas do Prius no Brasil por $R \$ 120.830$ [página da internet]. São Paulo: Auto Esporte [Acesso em 12 Mai 2014]. Disponível em: http://g1.globo.com/carros/noticia/2013/01/toyota-comeca-vendas-do-prius-no-brasilpor-r-120830.html

12 Bakker S. The car industry and the blow-out of the hydrogen hype. Energy Policy. 2010; 38(11):6540-4.

13 Campanari S, Manzolini G, Garcia de la Iglesia F. Energy analysis of electric vehicles using batteries or fuel cells through well-to-wheel driving cycle simulations. Journal of Power Sources. 2009; 186(2):464-77.

\footnotetext{
* Contribuição técnica ao $69^{\circ}$ Congresso Anual da ABM - Internacional e ao 14ํㅡㄹ ENEMET - Encontro Nacional de Estudantes de Engenharia Metalúrgica, de Materiais e de Minas, 21 a 25 de julho de 2014, São Paulo, SP, Brasil.
} 